\title{
1 Roosting ecology and the evolution of bat landing maneuvers
}

3 David B. Boerma ${ }^{1, *}$ and Sharon M. Swartz ${ }^{1,2}$

4

$5{ }^{1}$ Department of Ecology and Evolutionary Biology, Brown University, Providence, RI 02906, USA;

$6 \quad{ }^{2}$ School of Engineering, Brown University, Providence, RI 02906, USA

\section{7}

$8 \quad$ *Author for correspondence (boermadavid@gmail.com)

\section{Abstract}

11 Biomechanics is poised at the intersection of organismal form, function, and ecology, and forms a

12 practical lens through which to investigate evolutionary linkages among these factors. We

13 conducted the first evolutionary analysis of bat flight dynamics by examining the phylogenetic

14 patterning of landing mechanics. We discovered that bats perform stereotyped maneuvers that are

15 correlated with landing performance quantified as impact force, and that these are linked with

16 roosting ecology, a critical aspect of bat biology. Our findings suggest that bat ancestors performed

17 simple, four-limbed landings, similar to those performed by gliding mammals, and that more

18 complex landings evolved in association with novel roost types. This explicit connection between

19 ecology and biomechanics presents the opportunity to identify traits that are associated with a

20 locomotor behavior of known ecological relevance, thus laying the foundation for a broader

21 understanding of the evolution of flight and wing architecture in this extraordinarily successful

22 mammalian lineage.

\section{Introduction}

25 Morphologists and biomechanicians often study organismal evolution as a function of

26 three interrelated factors: structure (morphology), function (mechanics or behavior), and context

27 (ecology). Detecting linkages among traits from these categories and discerning where trait shifts

28 correspond with patterns of diversification not only provides evidence of selection but can also

29 point to specific drivers of adaptive radiations, which are a central phenomenon in evolution

30 (Arbour et al., 2019; Burress and Wainwright, 2019; Dakin et al., 2018; Eliason et al., 2020; 
31 Muñoz et al., 2018; Stroud and Losos, 2016). Within this framework, many investigations focus

32 on pairwise relationships between two of the three factors: the discipline of functional morphology

33 relates structure to function, whereas the discipline of ecomorphology relates structure with

34 environmental context. These fields reveal both the variety of forms that evolution has produced

35 and the details of how those forms work. Ultimately, however, each field omits the relationship

36 that can be most informative for understanding the process of evolution alongside its products: the

37 relationship between biomechanical function and ecological context. If "organismal performance

38 is the primary substrate upon which selection acts, and variation in performance often arises from

39 variation in biomechanics" (Higham et al., 2016), then directly probing the relationship between

40 biomechanical diversity and ecological diversity can point to specific traits that could be targets of

41 selection, and produce testable hypotheses about how form, function, and ecology interact to drive

42 diversification.

43 Coordinated shifts in form, function, and context are necessary for the evolution of new

44 locomotor modes, such as flight in the lineages that gave rise to bats, birds, insects, and pterosaurs.

45 Although often overlooked, the evolution of flight required not only the evolution of flight per se,

46 but also the evolution of landing maneuvers, which transition an animal from moving in air to a

47 standstill; one need only refer to the Greek myth of Daedalus and Icarus to learn that the capacity

48 for flight without the ability to safely land is untenable. For bats and most other flying animals,

49 landing maneuvers also provide access to the structures that constitute their homes, such as roosts,

50 nests, mounds, and hives. They rely on these structures to provide critical functions that extend

51 beyond simply serving as refugia from weather and predators. For example, roost location

52 determines the foraging grounds of many bat species; roosts serve as social spaces that facilitate

53 access to mates, maternal care, and meal sharing; and divergent roost preferences can drive niche

54 partitioning to permit co-occurrence of closely related species (Herrera et al., 2018; Kunz and

55 Lumsden, 2003; Voss et al., 2016; Wilkinson, 1984). Furthermore, roost types vary among bat

56 species and comprise a wide range of natural and human-made structures. These include bare

57 expanses of cave ceiling, crevices and clefts in rock walls, cavities in trees, the voids beneath

58 exfoliating tree bark, within the culms of bamboo, inside the funnels of furled leaves, and even

59 within pitcher plants (see (Kunz and Fenton, 2006) and (Altringham, 2011) for review). Roosting

60 ecology therefore plays an outsized role in defining the environmental mosaic in which bats survive 
61 and evolve. Roosting, along with other aspects of bat ecology, such as diet, foraging style, sensory

62 modalities, etc., shapes the behavioral and environmental context that drives changes in form,

63 function, performance, and ultimately diversity (Higham et al., 2016; Schluter, 2009).

64 Despite the importance of roosting ecology to extant bat diversity, we know little about

65 mechanistic factors that drive roost choices. Measures of biomechanical performance can yield

66 insight into microhabitat preferences (Moore et al., 2017), and for bats, the mechanics of landing

67 maneuvers may be linked to the physical properties of roosts. Specifically, landing dynamics may

68 facilitate access to particular roost types for some species and reduce access for others. Bat landing

69 maneuvers serve two basic functions: 1) body reorientation, and 2) velocity reduction. Body

70 reorientation positions the claws of the foot and/or thumbs to attach to the roost and transitions

71 the bat from a head-forward posture, with the vertebral column approximately parallel to the

72 ground, to the characteristic head-under-heels roosting posture of most species. Velocity reduction

73 modulates the bat's impact force with the roost and transitions its body from flight, with the center

74 of mass at a non-zero forward velocity, to roosting with the center of mass at rest.

75 To date, research has identified three landing maneuvers among four species, which are

76 named according to the number of points of contact the bat uses to attach to its landing site upon

77 contact. These maneuvers include two-point landing (both hindlimbs only), and two variants of a

78 four-point landing (both thumbs plus both hindlimbs) (Boerma et al., 2019; Riskin et al., 2009)

79 (Supplemental Videos 1 - 4). Each landing style also involves a characteristic sequence of body

80 rotations, and results in either relatively high or low impact forces normalized to bodyweight. Four-

81 point landings are rotationally simple, primarily involving body pitch, and result in higher impact

82 forces (>3 bodyweights), whereas two-point landings are the most rotationally complex, and result

83 in low peak impact forces ( $\leq 1$ bodyweight) (Boerma et al., 2019; Riskin et al., 2009). These studies

84 have suggested that landing maneuvers and roosting habits are mechanically linked such that high-

85 impact landings (four-point) are associated with roosting on compliant foliage or vertical surfaces,

86 whereas low-impact landings (two-point) are associated with roosting on stiff horizontal surfaces,

87 such as cave ceilings or tree hollows.

The broad biological importance of roosting ecology and interspecific variation in landing

89 mechanics offers an opportunity to discover how the biomechanical basis of landing performance

90 may underlie how bats take refuge and disperse within their environment. In the present study, we 
91 ask three questions relating to landing mechanics, roosting habits, and the potential associations

92 between them: 1) Do previously documented relationships between landing style and impact force

93 remain consistent across a more diverse sample of bats, 2) what is the evolutionary history of bat

94 landing maneuvers, and 3) is landing style linked to roosting ecology? We hypothesized that (i)

95 rotationally complex landing maneuvers would result in lower impact forces than rotationally

96 simple landing maneuvers, across species and body sizes; (ii) rotationally simple, four-point

97 landings are the ancestral condition for bats from which any other style must have evolved; and

98 (iii) landing styles are associated with the physical properties of the roosts to which they provide

99 access. With respect to this final hypothesis, we predicted that four-point landings would be

100 associated with compliant roosts, such as those constructed from foliage, because they could

101 absorb the high impact forces generated by this landing style and because multiple points of

102 contact enhance stability when landing on unstable targets (Boerma et al., 2019; Bonser, 1999;

103 Demes et al., 1995; Riskin et al., 2009). We also predicted that stiff roosts, such as cave ceilings or

104 tree cavities, would be associated with two-point landings because low impact forces could enhance

105 the control and precision of landings and reduce risk of injury when a flying bat decelerates rapidly

106 to attach to a stiff surface.

107

108 Results

109 Landing styles across species

110 We recorded 665 landings from 35 bat species, representing nine families. Of these, 15

111 species performed two-point landings, 5 performed three-point landings, and 15 performed four-

112 point landings, including Thyroptera tricolor, which performed a specialized four-point landing

113 maneuver; see below and Boerma et al., 2019) (Table 1, Supplemental Videos 1 - 4). Overall,

114 landing style was consistent within and among individuals of each species. Notable exceptions

115 include Artibeus jamaicensis, which performed two- (29\%) and three-point (71\%) landings, and

116 Miniopterus schreibersii, which performed two- (18\%), three- (36\%), and four-point (45\%) landings.

117 Pteropodid, vespertilionid, and mormoopid species performed four-point landings; emballonurid,

118 rhinolophid and hipposiderid species performed two-point landings; and phyllostomids performed

119 two-, three-, and four-point landings. 
Table 1: Study taxa, landing style observed, peak landing impact forces, and roosting ecology category. Roost categories are: cavity in standing tree (CST), exposed on standing stree (EST), unmodified foliage (FOL-UF), furled leaf-tubed (FOL-TB), foliage modified into leaf-tents (FOL-LT), termite or ant nests (TAN), rocks and/or caves (R/C), and rock crevices (CREV). Bolded categories indicate those used for comparative analyses; see text for further explanation. ${ }^{*}$ Data from Riskin et al. (2009). ${ }^{\dagger} H$. pratti performed landings that were qualitatively similar to two-point landings, however, following attachment with the hindlimbs, bats flexed the spine ventrally and extended the shoulder and elbow joints to lift the thumb claws ventrally toward their attachment site on the landing plate. Because the thumbs were attached only after the contact during landing, we classify landings by $H$. pratti as two-point in our analysis. ${ }^{\ddagger} T$. tricolor performs a specialized four-point landing maneuver (see Boerma et al., 2019). See Figure 1-Source Data 1 for raw data used to generate this table.

\begin{tabular}{|c|c|c|c|c|c|c|}
\hline Taxon & $\begin{array}{l}\mathrm{N} \text { (total } \\
\text { observed } \\
\text { landings, } \\
\text { individuals) }\end{array}$ & $\begin{array}{l}\mathrm{N} \text { (Force } \\
\text { recordings, } \\
\text { individuals) }\end{array}$ & Landing Style & $\begin{array}{c}\text { Peak } \mathrm{F}_{\text {tot }} \\
\text { (Bodyweight } \\
\text { BW) } \\
\text { (mean } \pm \text { s.d) }\end{array}$ & $\begin{array}{l}\text { Roosting } \\
\text { Ecology }\end{array}$ & Source(s) \\
\hline \multicolumn{7}{|l|}{ Yinterpochiroptera } \\
\hline \multicolumn{7}{|l|}{$\overline{\text { Pteropodidae }}$} \\
\hline Cynopterus brachyotis* & 30,3 & 30,3 & 4-point & $3.83 \pm 1.23$ & $\begin{array}{l}\text { FOL-UF, FOL- } \\
\text { LT }\end{array}$ & $\begin{array}{l}\text { (Campbell et al., 2006; } \\
\text { Funakoshi and Zubaid, 1997; } \\
\text { Tan et al., 1997) }\end{array}$ \\
\hline Rousettus aegyptiacus & 57,3 & - & 4-point & - & $\mathrm{R} / \mathrm{C}$ & $\begin{array}{l}\text { (Herzig-Straschil and } \\
\text { Robinson, 1978; Kwiecinski } \\
\text { and Griffiths, 1999; Thomas } \\
\text { and Fenton, 1978) }\end{array}$ \\
\hline \multicolumn{7}{|l|}{ Hipposideridae } \\
\hline Hipposideros pratti & 7,1 & - & 2-point ${ }^{\dagger}$ & - & $\mathrm{R} / \mathrm{C}$ & $\begin{array}{l}\text { (Niu et al., 2007; Zhang et al., } \\
\text { 2009)( }\end{array}$ \\
\hline \multicolumn{7}{|l|}{ Rhinolophidae } \\
\hline Rhinolophus hipposideros & 33,3 & 32,3 & 2-point & $0.52 \pm 0.04$ & $\mathrm{R} / \mathrm{C}$ & (Aulagnier et al., 2018) \\
\hline Rhinolophus mehelyi & 30,4 & 30,4 & 2-point & $0.60 \pm 0.17$ & $\mathrm{R} / \mathrm{C}$ & (Aulagnier et al., 2018) \\
\hline Rhinolophus euryale & 22,4 & 22,4 & 2-point & $1.03 \pm 0.44$ & $\mathrm{R} / \mathrm{C}$ & (Aulagnier et al., 2018) \\
\hline Rhinolophus ferrumequinum & 31,4 & 31,4 & 2-point & $1.29 \pm 1.00$ & $\mathrm{R} / \mathrm{C}$ & (Aulagnier et al., 2018) \\
\hline \multicolumn{7}{|l|}{ Yangochiroptera } \\
\hline \multicolumn{7}{|l|}{ Emballonuridae } \\
\hline Rhynchonycteris naso & 6,1 & - & 2-point & - & EST, FOL-UF & $\begin{array}{l}\text { Sources cited by (Fenton et al., } \\
\text { 2001; Voss et al., 2016) }\end{array}$ \\
\hline Saccopteryx bilineata & 2,1 & - & 2-point & - & CST, EST & $\begin{array}{l}\text { Sources cited by (Voss et al., } \\
\text { 2016) }\end{array}$ \\
\hline
\end{tabular}


Thyroptera tricolor

Mormoopidae

Pteronotus mesoamericanus

Pteronotus davyi

Phyllostomidae

Glossophaga soricina *

Chrotopterus auritus

Mimon cozumelae

Lophostoma evotis

Gardnernycteris crenulatum

Carollia sowelli

Carollia perspicillata*

Sturnira parvidens

Uroderma bilobatum

Dermanura phaeotis

Artibeus jamaicensis

Artibeus intermedius

Artibeus watsoni

Miniopteridae

Miniopterus schreibersii

30,3

17,2

11,2

5, 1

49,5

3, 1

20,4

9,1

3,1

16,3

50,5

23,5

2, 1

25,5

21,3

11,2

5,1
Micronycteris schmidtorum

44,14

point

$6.98 \pm 1.89$

FOL-TB

(Wilson and Findley, 1977)

Vespertilionidae 4-point $\quad-\quad \mathrm{R} / \mathrm{C}$, CST $\quad$ Sources cited by (Voss et al.,

4-point $\quad-\quad \mathrm{R} / \mathrm{C}$

016)

Sources cited by (Fenton et al., 2001)

Sources cited by (Voss et al., 2016)

Sources cited by (Voss et al., 2016)

Sources cited by (Fenton et al., 2001; Simmons and Voss,

1998; Voss et al., 2016)

(Fenton et al., 2001; Reid,

2009)

Sources cited by (Voss et al., 2016)

(Fenton et al., 2001); Sources cited by (Voss et al., 2016)

(Cloutier and Thomas, 1992;

Fenton et al., 2001; Reid, 2009; Voss et al., 2016)

$\begin{array}{cccl}11,3 & \text { 4-point } & 4.22 \pm 2.29 & \text { FOL-UF, CST } \\ 2,1 & \text { 3-point } & 3.95 & \text { FOL-LT } \\ 10,3 & \text { 3-point } & 2.73 \pm 2.32 & \text { FOL-LT } \\ 21,3 & \text { 2-, 3-point } & 1.19 \pm 0.30 & \text { R/C, FOL-LT } \\ 11,2 & \text { 2-point } & 1.03 \pm 0.24 & \text { R/C, CST, FOL- } \\ & & & \text { UF, FOLLT } \\ - & \text { 3-point } & - & \text { FOL-LT }\end{array}$

(Fenton et al., 2001, 2000)

(Barbour, 1932; Timm, 1985)

(Timm, 1985)

Sources cited (Timm, 1985)

(Reid, 2009)

(Chapman, 1932; Chaverri and Kunz, 2006; Choe and

Timm, 1985)

(Aulagnier et al., 2018;

Nowak, 1999) 
Myotis keaysi

Myotis daubentonii

Myotis myotis

Myotis capaccinii

Rhogeesa aeneus

Eptesicus fuscus

Eptesicus serotinus

Hypsugo savii
5, 1

10, 1

12,2

16,4

3,1

10,1

10, 1

10, 1

Totals:

665, 96

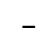

4-point

4-point

4-point

4-point

4-point

4-point

4-point

4-point 


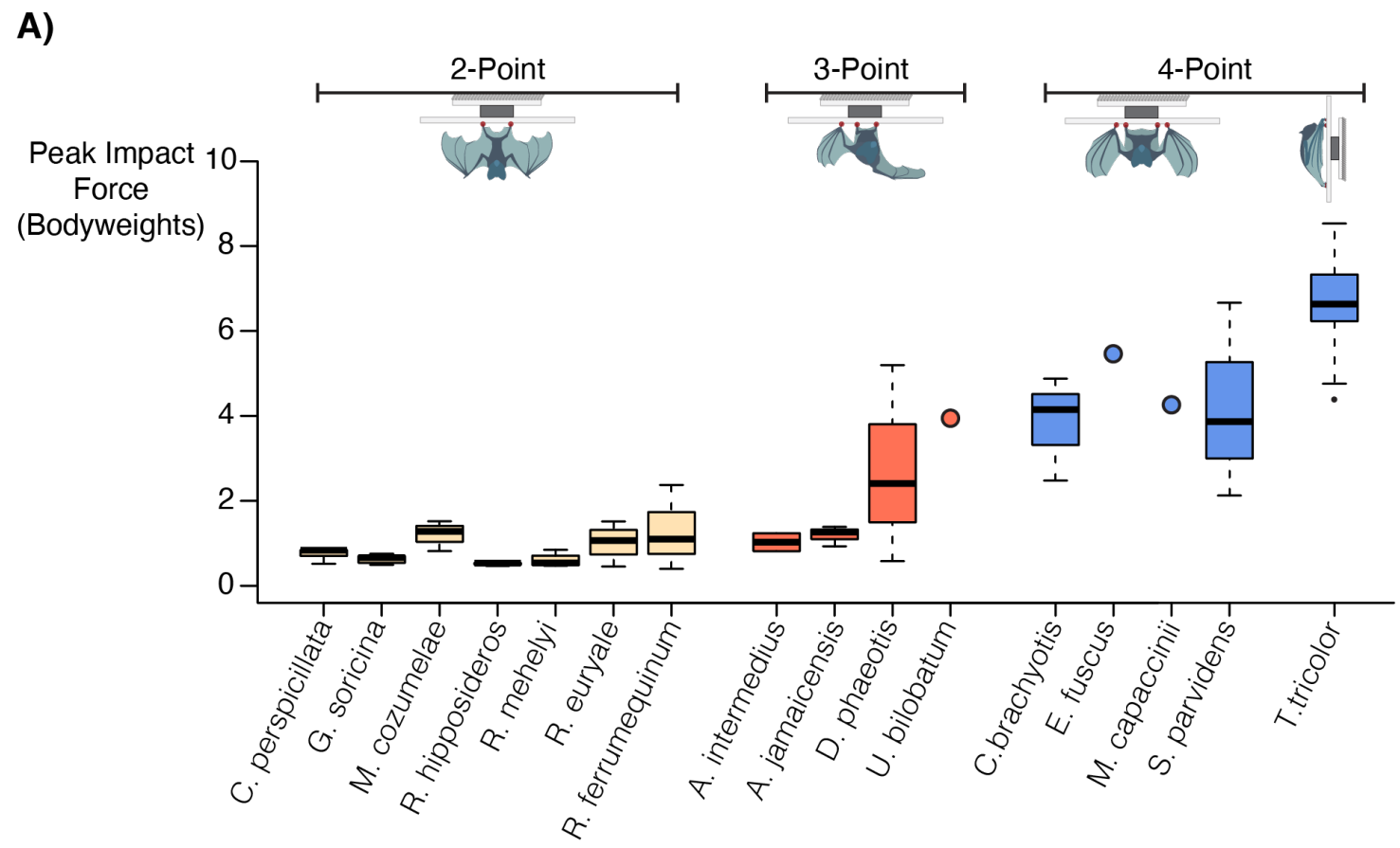

B)

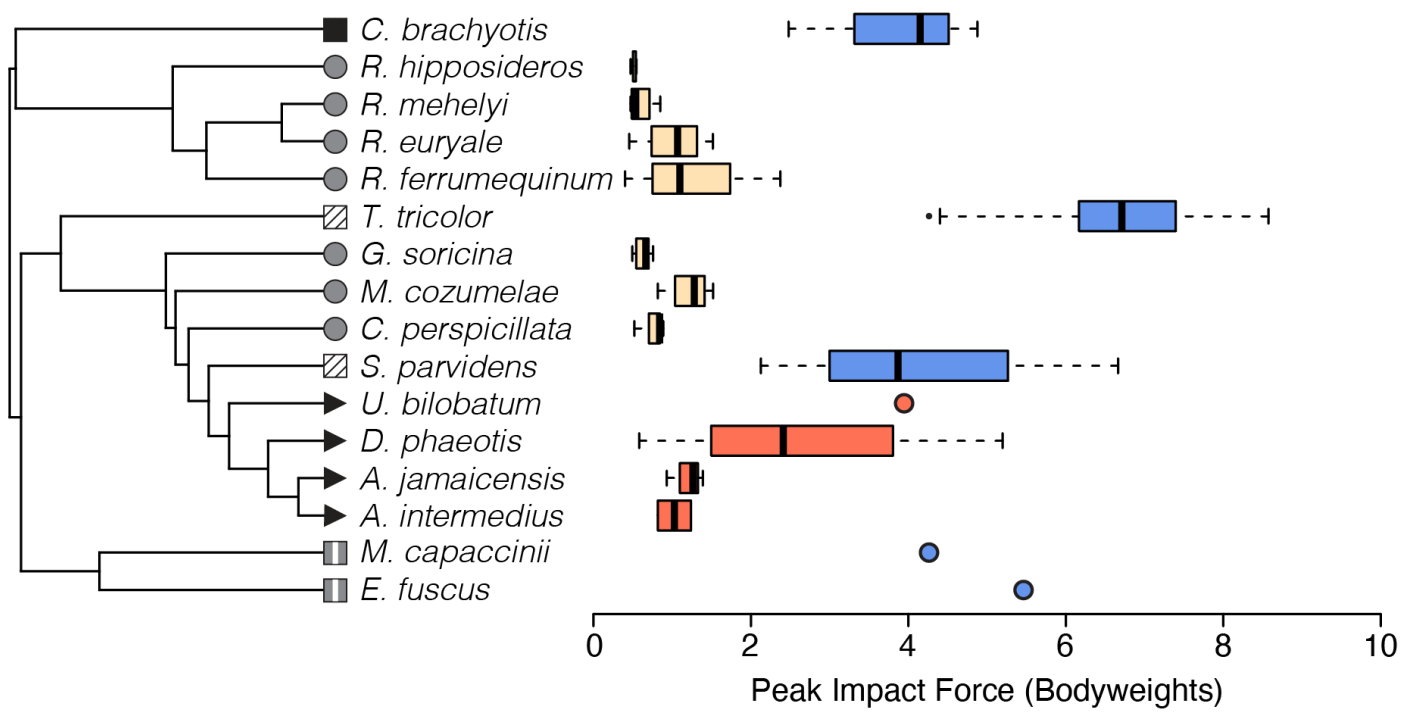

Figure 1: Peak landing impact forces (excluding M. schreibersii; see table 1 for sample sizes). Box and whisker plots show the median and interquartile range. (A) Landing impact forces arranged by landing style. (B) Landing impact forces arranged phylogenetically (tree adapted from Shi and Rabosky, 2015). Two-point landings are denoted by yellow boxes and circle icons at branch tips, three-point landings by red boxes and triangle icons, and four-point landings by blue boxes and square icons. Icon fill color represents roosting ecology: solid gray = stiff horizontal roosts; grey with vertical white stripe = crevices; black = leaf tents; and hatched $=$ unmodified foliage. Legend also provided in figure 2. See Figure 1-Source Data 1 for raw impact force measurements for each landing and Figure 1-Source Data 2 for each individual's mean peak impact force, the latter of which was used to generate these figures. See Source Code File 1 for R code to reproduce these plots. 
Landing impact force increases with points of contact across landing styles

Two-point landings from 32 individuals of 15 species, from 4 families, uniformly resulted in low peak impact forces, with a mean of $0.95 \pm 0.54 \mathrm{BW}$ (mean \pm s.d.,). Four-point landings resulted in higher impact forces: $3.72 \pm 1.71 \mathrm{BW}$ ( $\mathrm{n}=10$ individuals, 5 species). Three-point landings were intermediate in magnitude and more variable; mean impact was $1.71 \pm 1.44 \mathrm{BW}$ ( $n=12$ individuals, 4 species). The specialized four-point landings of T. tricolor resulted in the highest impact forces, 6.98 $\pm 1.89 \mathrm{BW}$ (n=14 individuals) (Boerma et al., 2019). Phylogenetic generalized least squares regression (PGLS, T. tricolor omitted, see Phylogenetic Analyses in Methods) revealed that log peak impact force increases significantly with points of contact across species $\left(\mathrm{DF}=14, \mathrm{~F}=33.47, \mathrm{p}=4.726 \times 10^{-5}\right)$. Phylogenetic ANOVA (T. tricolor omitted) corroborated that landing style has a significant effect on log peak impact force $(F=14.04, p=0.0099)$. Pairwise posthoc tests with Holm-Bonferroni correction show that two-point landings result in significantly lower impact forces than four-point landings $(\mathrm{t}=-5.26, \mathrm{p}=0.0078)$, and that the intermediate impact forces associated with three-point landings are not statistically different from either twopoint $(t=2.49, \mathrm{p}=0.2266)$ or four-point landings $(t=-2.45, \mathrm{p}=0.2266)$ (see Source Code File 3 and PGLS phylANOVA-Source Data 1 for the raw data and code used to conduct these analyses).

Four-point landings are ancestral and preceded multiple independent evolutions of two-and three-point landings

We simulated 1000 stochastic character maps of landing style on a phylogeny pruned to our sampled taxa (figure 2). These simulations estimated that four-point landings were ancestral (Posterior Probability $(\mathrm{PP})=0.862$ ), and that landing style shifted an average of 7.903 times. Of these shifts, 3.161 state changes occurred from four- to two-point landings. This was the most common evolutionary shift and occurred at multiple locations in the bat phylogeny. Additional state changes were concentrated among bats in the family Phyllostomidae. In this clade, 2.061 shifts occurred from two- to three-point landings, and we detected 1.427 reversals from two- to four-point landings (in S. parvidens). Our reconstruction also estimated 0.636 state changes from three- to four-point landings, 0.384 state changes from four- to three-point landings, and 0.234 state changes from three- to two-point landings. The mean proportion of time spent in each state 
161 was 54.14\% in four-point landings, 38.90\% in two-point landings, and 7.06\% in three-point 162 landings.

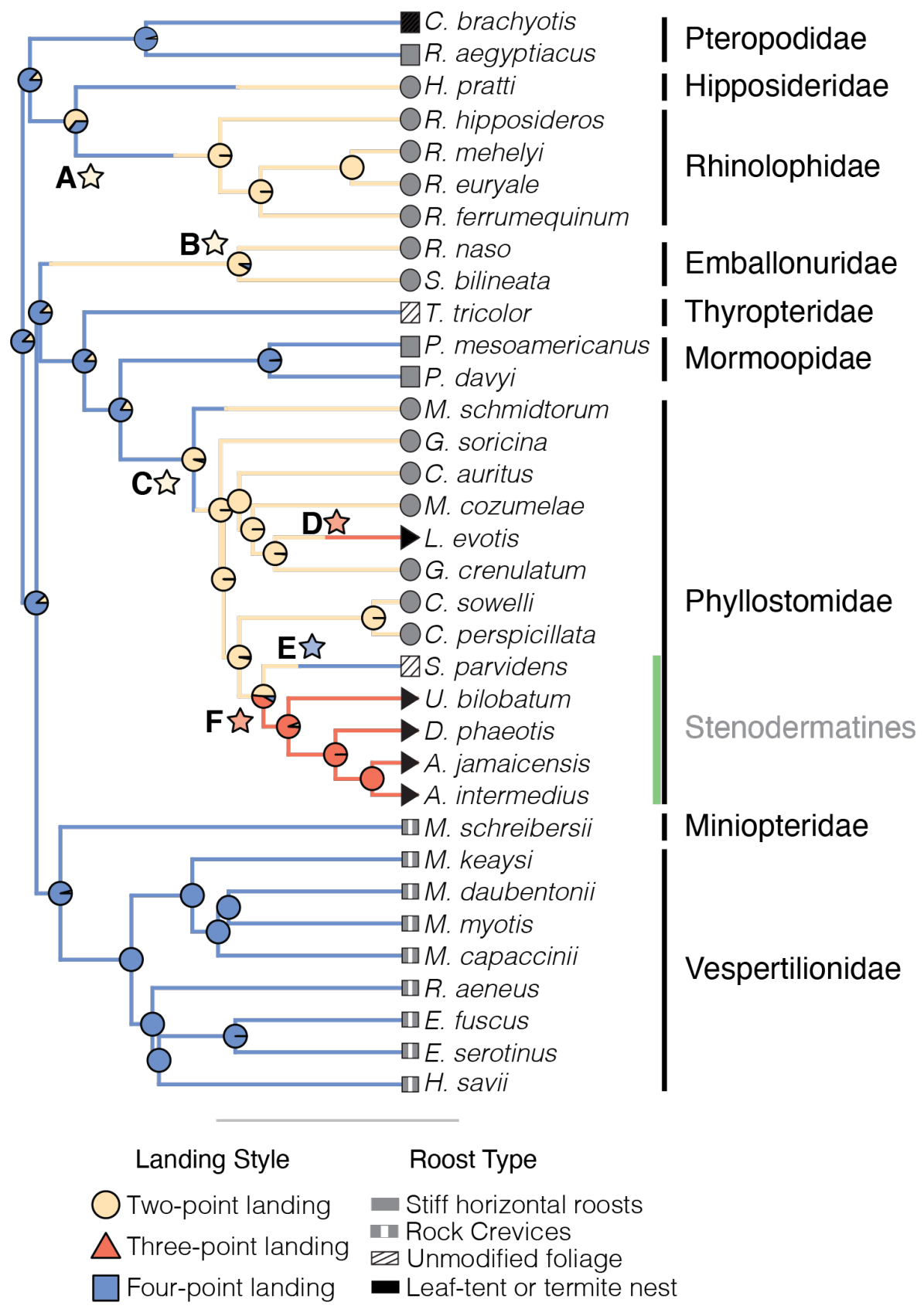

Figure 2: Stochastic map of landing styles. Pie charts at the nodes show posterior probabilities. Stars A-E mark shifts in landing style. Tip shapes denote landing style, and tip fill denotes the roost type used in the aggregated model of phylogenetic logistic regression. Black vertical bars to the right of the species names denote families; the green line highlights the subfamily Stenodermatinae. Phylogeny adapted from Shi and Rabosky (2015). See Figure 2-Source Data 1, Figure 2-Source Data 2, and Source Code File 2 for the raw data and code used to generate this figure. Full posterior probabilities are provided in Supplemental Files 1 and 2 . 
Among the taxa we sampled, we detected three independent shifts to from four- to twopoint landings. These occurred at the base of the clade giving rise to the Rhinolophidae and Hipposideridae $\left(\mathrm{PP}_{\text {two-point }}=0.642\right)$, at the base of Emballonuridae $\left(\mathrm{PP}_{\text {two-point }}=0.92\right)$, and (iii) at the base of the Phyllostomidae $\left(\mathrm{PP}_{\text {two-point }}=0.949\right)$ (figure $\left.2 \mathrm{~A}, \mathrm{~B}, \& \mathrm{C}\right)$. Three-point landings evolved relatively recently, emerging first in the common ancestor of the phyllostomid subfamily Stenodermatinae (figure 2F). This ancestor possessed equal probability of performing two- or threepoint landings $\left(\mathrm{PP}_{\text {two-point }}=0.464 ; \mathrm{PP}_{\text {three-point }}=0.463\right)($ figure $2 \mathrm{~F})$. In this species sample, the common ancestor of tent-roosting phyllostomids (stenodermatines excluding S. parvidens) was most

172 likely to perform three-point landings $\left(\mathrm{PP}_{\text {three-point }}=0.921\right)$. Three-point landings also arose in the

173 phyllostomid L. evotis (figure 2D). We detected one reversal from two- to four-point landings in the

174 phyllostomid S. parvidens (figure 2E). Four-point landings, the ancestral condition, persisted in

175 pteropodids, mormoopids, and vespertilionids, based on analysis of this sample.

177 Landing styles are associated with the physical properties of roosts across species

178 We investigated the relationship between roosting ecology and landing style by using phylogenetic 179 logistic regression to compare landing style with roosting ecology using alternative roost

180 classification schemes, which aggregated roost categories with similar physical characteristics (table

181 2). Compared to the null model, our aggregated model had greater explanatory power for

182 predicting landing style from roosting ecology, as indicated by AIC score. Our null model, which

183 tested for association between roosting habits and landing style using the most common roost type

184 for each species, revealed a significant positive association only between cavity-roosting and two-

185 point landings $\left(\beta_{\text {NullCST-2pt }}=3.862 ; \mathrm{p}_{\text {Null,CST-2pt }}=0.01701\right)$. Aggregating roosting categories according

186 to physical properties, such as compliance, orientation, and spatial constraint, allowed us to test

187 the hypothesis that these physical properties are significantly associated with the mechanics of the

188 three known landing styles. We found that two-point landings were positively associated with stiff,

189 horizontal roosts, such as caves and cavities $\left(\beta_{\mathrm{Agg},[\mathrm{CST}+\mathrm{EST}+\mathrm{R} / \mathrm{C}+2 \mathrm{pt}}=4.367 ; \mathrm{p}_{\mathrm{Agg},[\mathrm{CST}+\mathrm{EST}+\mathrm{R} / \mathrm{C}-2 \mathrm{pt}}=\right.$

190 0.008089). Three-point landings were positively associated with roosting in spatially constrained

191 structures, such as leaf-tents and termite nests $\left(\beta_{\text {Agg,|tent }+\tan -3 \mathrm{pt}}=3.525 ; \mathrm{p}_{\mathrm{Agg},[\mathrm{ten} t+\tan ]-3 \mathrm{pt}}=0.04354\right)$. Four-

192 point landings were negatively associated with roosting beneath stiff, horizontal structures

$193\left(\beta_{\mathrm{Agg},[\mathrm{CST}+\mathrm{EST}+\mathrm{R} / \mathrm{C}]-4 \mathrm{pt}}=-2.144 ; \mathrm{p}_{\mathrm{Agg},[\mathrm{CST}+\mathrm{EST}+\mathrm{R} / \mathrm{C}]-4 \mathrm{pt}}=0.03589\right)$. 
Table 2: Correlations between landing style and roosting ecology from phylogenetic logistic regressions. We provide Firth-corrected coefficient estimates (ß) with bootstrapped 95\% confidence intervals (in brackets) and Wald p-values (in italics) to denote significant associations between roost type. Significant p-values are

bolded and set within shaded cells. AIC scores provide comparison between our Null and Aggregated model (models with smaller AIC are preferred; differences are meaningful when 22). P-values are conditional upon phylogenetic signal, $\alpha$, where values near 0 denote strong phylogenetic signal and values approaching 1

indicate weak phylogenetic signal. Roosting ecology categories correspond with those listed in Table 1: cavity in standing tree (CST), exposed on standing tree (EST), rocks and/or caves (R/C), termite or ant nests (TAN), foliage-leaf tent (FOL-LT), unmodified foliage (FOL-UF), and rock crevices (CREV). See Table 2-Source Data 1 and Source Code File 3 for data and code used to produce this table.

\begin{tabular}{|c|c|c|c|c|c|c|c|c|c|c|}
\hline \multirow{2}{*}{ Model } & \multirow{2}{*}{ Landing } & CST & EST & $\mathrm{R} / \mathrm{C}$ & TAN & FOL-LT & FOL-UF & CREV & \multirow{2}{*}{$\mathrm{AIC}$} & \multirow{2}{*}{$\alpha$} \\
\hline & & \multicolumn{7}{|c|}{$ß=$ Mean coefficient estimate, [lower CI, upper CI], pval } & & \\
\hline \multirow{3}{*}{ 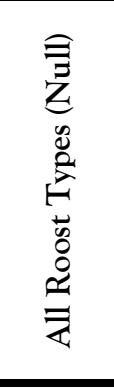 } & 2-pt. & $\begin{array}{c}3.862 \\
{[0.637,5.413]} \\
0.01701\end{array}$ & $\begin{array}{c}2.944 \\
{[-0.053,3.700]} \\
0.26658\end{array}$ & $\begin{array}{c}1.978 \\
{[-1.225,4.072]} \\
0.12250\end{array}$ & $\begin{array}{c}1.748 \\
{[-0.869,3.164]} \\
0.2981\end{array}$ & $\begin{array}{c}0.594 \\
{[-2.345,2.482]} \\
0.68152\end{array}$ & $\begin{array}{c}1.027 \\
{[-1.225,2.655]} \\
0.50338\end{array}$ & $\begin{array}{c}-1.277 \\
{[-2.737,0.216]} \\
0.30867\end{array}$ & 40.61 & 0.0036 \\
\hline & 3-pt. & $\begin{array}{c}-0.098 \\
{[-1.708,2.136]} \\
0.8973\end{array}$ & $\begin{array}{c}-0.135 \\
{[1.099,1.408]} \\
0.9097\end{array}$ & $\begin{array}{c}-0.975 \\
{[-2.402,0.471]} \\
0.2719\end{array}$ & $\begin{array}{c}2.459 \\
{[-0.580,3.340]} \\
0.4405\end{array}$ & $\begin{array}{c}1.608 \\
{[-0.524,4.513]} \\
0.3182\end{array}$ & $\begin{array}{c}0.090 \\
{[-2.402,0.471]} \\
0.2719\end{array}$ & $\begin{array}{c}-0.453 \\
{[-1.243,0.680]} \\
0.7954\end{array}$ & 30.09 & 0.0030 \\
\hline & 4-pt. & $\begin{array}{c}-0.657 \\
{[-2.108,0.557]} \\
0.9017\end{array}$ & $\begin{array}{c}-0.237 \\
{[-1.627,-1.315]} \\
0.8468\end{array}$ & $\begin{array}{c}-0.237 \\
{[-1.812,1.878]} \\
0.7521\end{array}$ & $\begin{array}{c}-0.234 \\
{[-1.535,1.122]} \\
0.8523\end{array}$ & $\begin{array}{c}-0.237 \\
{[-1.275,1.063)} \\
0.7938\end{array}$ & $\begin{array}{c}1.081 \\
{[-0.995,3.199]} \\
0.5321\end{array}$ & $\begin{array}{c}0.190 \\
{[-1.020,1.090]} \\
0.9017\end{array}$ & 42.35 & 0.0045 \\
\hline \multirow{3}{*}{ 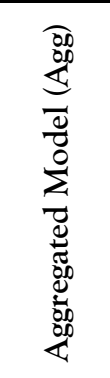 } & 2-pt. & & $\begin{array}{c}4.367 \\
{[2.023,5.428]} \\
0.008089\end{array}$ & & \multicolumn{2}{|c|}{$\begin{array}{c}1.648 \\
{[-0.851,3.065]} \\
0.366708\end{array}$} & $\begin{array}{c}1.346 \\
{[-0.519,3.345]} \\
0.580319\end{array}$ & $\begin{array}{c}-2.947 \\
{[-3.023,-1.079]} \\
0.366708\end{array}$ & 33.03 & 0.5251 \\
\hline & 3-pt. & & $\begin{array}{c}-0.631 \\
{[-2.476,1.681]} \\
0.76677\end{array}$ & & \multicolumn{2}{|c|}{$\begin{array}{c}3.525 \\
{[0.231,5.184]} \\
0.04354\end{array}$} & $\begin{array}{c}1.356 \\
{[-0.532,3.348]} \\
0.57546\end{array}$ & $\begin{array}{c}-2.937 \\
{[-3.00,-0.248]} \\
0.05402\end{array}$ & 20.28 & 0.9100 \\
\hline & 4-pt. & & $\begin{array}{c}-2.144 \\
{[-4.498,-0.337]} \\
0.03589\end{array}$ & & \multicolumn{2}{|c|}{$\begin{array}{c}-1.133 \\
{[-3.681,1.890]} \\
0.38111\end{array}$} & $\begin{array}{c}1.308 \\
{[-2.236,2.538]} \\
0.56684\end{array}$ & $\begin{array}{c}0.703 \\
{[-0.637,2.950]} \\
0.51964\end{array}$ & 32.33 & 0.0076 \\
\hline
\end{tabular}




\section{Discussion}

Using a combination of field and lab-based measurements, we investigated functional links between landing mechanics and roosting ecology, which is a critical biological factor for bats. Our measurements of landing style in 35 bat species and peak impact forces in a 17 species subset of this group shows that landing impact force increases with the number of points of contact a bat uses to land, i.e. impact force varies according to landing style even after correction for phylogenetic relationships among the study species. Moreover, we observe that bat landing styles

212 are associated with patterns of roost use: rotationally simple, high-impact four-point landings are

213 ancestral for bats, and rotationally complex two-point landings evolved independently multiple

214 times in lineages that habitually roost beneath stiff surfaces. Furthermore, in the stenodermatines,

215 a subfamily of the Phyllostomidae that shows a reversal from roosting in cavities (stiff surfaces) to roosting in foliage (compliant surfaces) (Garbino and Tavares, 2018), we observe a concomitant

217 reversal from low-impact two-point landings to higher-impact three- and four-point landings.

218 Three-point landings, which we describe for the first time in the present study, arose twice among

219 our sampled taxa, each time in species that roost within spatially constrained horizontal roosts,

220 such as leaf tents or evacuated termite nests.

Roosting ecology and the evolution of bat landing maneuvers

Four-point landings, the ancestral condition for bat landings, are performed by nearly half

224 of the species in our sample (15 of 35). These landings were negatively associated with roosting

225 beneath stiff, horizontal surfaces (e.g., tree cavities and cave ceilings), but are not strictly associated

226 with compliant foliage roosts across the bat phylogeny, as has been hypothesized in earlier

227 investigations (Riskin et al., 2009). This foliage-roost hypothesis is weakly supported in the

228 phyllostomids we examined (e.g., S. parvidens) and for T. tricolor, both of which are foliage roosting 229 species that employ four-point landings. However, our sampling of pteropodids, mormoopids, and

230 vespertilionids, which included bats that habitually roost beneath stiff surfaces, such as cave

231 ceilings, and those that land on vertical walls and roost within rock crevices (vespertilionids), did

232 not show a clear correlation between four-point landing and foliage roosting. Broader sampling

233 among pteropodids and mormoopids could reveal additional patterns of roost use and landing 
234

235

236

237

238

239

240

241

242

243

244

245

246

247

248

249

250

251

252

253

254

255

256

257

258

259

260

261

262

263

mechanics. However, our results suggest that landing maneuvers in these three families are not as labile as in phyllostomids or rhinolophids. In the case of crevice-roosting bats, all of which are vespertilionids in this sample, four-point landings may offer functional opportunities despite the higher impact forces typically incurred on stiff substrates. These include facilitating more rapid access to interstices in the walls of cliffs, caves, trees, and human-made structures compared to other landing styles. Landing with four points of contact immediately places all limbs on the substrate, thus allowing for immediate transition from flight to landing to terrestrial locomotion (crawling) along the roost surface. This rapid locomotor transition could minimize the time required to locate crevice refuges (Supplementary Video 5, M. myotis) and reduce exposure to predators or adverse climatic conditions.

We observed convergent shifts from four-point to two-point landings at three nodes in the phylogeny (figure $2 \mathrm{~A}, \mathrm{~B}$, and $\mathrm{C}$ ), each representing a common ancestor of a lineage characterized by roosting beneath stiff, horizontal roosts (table 2). These shifts support the hypothesis that rotationally complex, low-impact two-point landings evolved in association with the physical properties of roosts in these lineages. Further support for this hypothesis is found among the phyllostomids in particular, in which secondary reversals away from stiff horizontal roosts (e.g., cavity or cave-roosting) to roosting in foliage or within spatially constrained structures on vegetation (e.g., leaf-tents and abandoned termite nests), corresponded with shifts from two-point to four- or three-point landings (figure 2D, E, and F). Apart from L. evotis, which roosts in termite nests, we documented high-impact three- and four-point landings only among bats in the phyllostomid subfamily Stenodermatinae (figure 2, taxa highlighted by the green vertical line), the lineage in which foliage roosting re-arose within Phyllostomidae (Garbino and Tavares, 2018). If bat landing maneuvers are adapted to the physical properties of roosts, this transition from lowimpact to high-impact landings at the node with a corresponding shift from stiff to compliant roosts could signal relaxed selective pressure for low-impact landings.

The stenodermatines are a relatively recent radiation (Amador et al., 2018; Rojas et al., 2016; Shi and Rabosky, 2015), and they show diversification rates that are approximately twice as high those background rates for Chiroptera (Dumont et al., 2012; Shi and Rabosky, 2015).

Previous work has identified shifts in diet, sensory modalities, and associated cranial morphology as key innovations that led to this rapid diversification (Arbour et al., 2019; Dumont et al., 2014, 
2012; Santana et al., 2012), but some have speculated that shifts toward foliage roosting may have also contributed to increased speciation rates in this clade (Garbino and Tavares, 2018; Voss et al., 2016). Here, we document transitions in this lineage from two-point to three- and four-point landings, and thus hypothesize that these evolutionary shifts in landing mechanics could be included among the factors contributing to the recent evolutionary success of the stenodermatines.

The hypothesis that convergence in roosting habits is associated with convergence of

272 landing style across the bat phylogeny is implicit in our prediction that roosting ecology and

273 landing style are linked. Our findings largely supported this hypothesis, but one intriguing

274 example of where results diverged from this pattern is in lineages that convergently evolved a

275 highly derived roosting ecology - tent-making. Tent-making refers to a behavior in which bats

276 weaken the veins of large leaves by biting them so that portions of the leaf droop to create a tent-

277 like shelter (Barbour, 1932; Kunz and Fenton, 2006; Kunz and Lumsden, 2003; Tan et al., 1997;

278 Timm, 1987). Leaf tents can take multiple forms (see Kunz and Lumsden 2003 for review), but

279 seem to function primarily as refugia from climate, rather than from predators (Tan et al., 1997).

280 This behavior independently arose in at least three species in the family Pteropodidae (represented

281 by C. brachyotis in our sample), and several species in the family Phyllostomidae (subfamily

282 Stenodermatinae, figure 2) (Kunz and Lumsden, 2003). Among the species in our study that

283 convergently evolved this derived roosting ecology, we observed family-level differences in landing

284 maneuvers, including the number of points of contact (three vs. four) and limb contact order

285 (hindlimbs first in three-point landings vs. thumbs first in four-point landings). Despite these

286 differences, however, three-point and four-point landings share similar degrees of rotational

287 complexity and result in similarly high impact forces (Figure 1).

288 This observation suggests a many-to-one mapping of landing mechanics to landing impact

289 force for species that roost in leaf tents; that is, although three- and four-point landings differ

290 kinematically, they result in a similar functional outcome (high impact forces), and their

291 differences may be due simply to the different evolutionary starting points of extant pteropodids

292 and stenodermatines (Wainwright et al., 2005). The most recent common ancestor of

293 stenodermatines and other phyllostomids in our sample most likely roosted in cavities (Garbino 


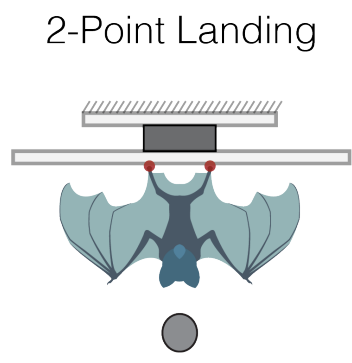

Caves/Hollows

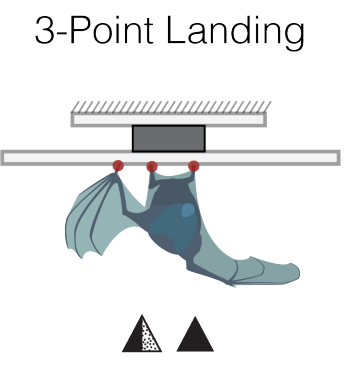

Leaf-tent
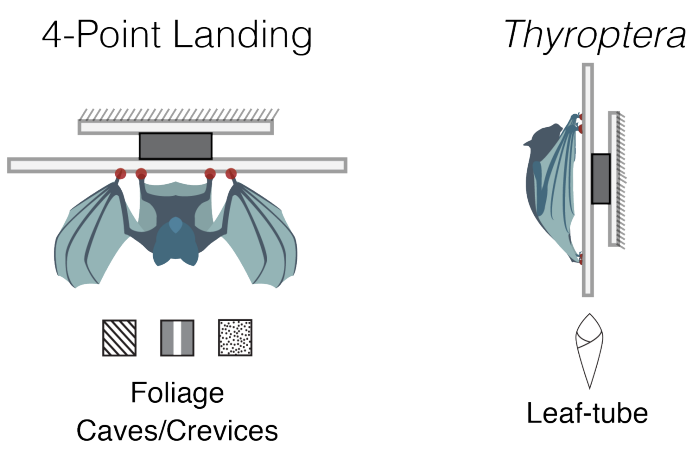

Stiff, Horizontal

Roosting Ecology

Compliant, Vertical

Pitch, Yaw, \& Roll

Rotational Complexity

Primarily Pitch

Low impact force

\section{Control over impact force}

High impact force

Figure 3. Continuum of landing style, roosting ecology, and landing mechanics. The mechanics of bat landings correspond with patterns of roost use among sampled bats.

and Tavares, 2018) and performed two-point landings $\left(\mathrm{PP}_{\text {two-point }}=0.978\right)$. Thus, this common ancestor likely landed with low impact force, using only the two hindlimbs as points of contact. Under our hypothesis, the transition to roosting in compliant leaf-tents would have reduced the selective pressure on low-impact landings, thus permitting a shift to higher-impact three-point landings that retained the feet-first contact order but added the thumb as a stabilizing point of contact. In contrast, the common ancestor of the pteropodids (which include C. brachyotis) performed four-point landings $\left(\mathrm{PP}_{\text {four-point }}=0.95\right)$, a landing style already amenable to roosting in compliant leaf tents which can absorb the high-impact landings.

Other factors that may influence landing style

We focused on associations between landing mechanics and roosting ecology in the present study, but other traits could also influence diversity of landing maneuvers among bats. Here we highlight a couple, including sensory ecology and wing morphology.

A bat's ability to sense the location, geometry, and surface characteristics of a potential landing site contributes to its capacity to execute accurate, precise landings. Therefore, variation in sensory ecology, specifically echolocation capacity and call structure, could also influence the landing maneuvers of bats. Most bats navigate their environments and detect prey using laryngeal 
311 echolocation, and the structure of these echolocation calls, including amplitude, frequency, and

312 rate, differs among species and tasks in ways that trade off between target resolution and detection

313 distance (Geva-Sagiv et al., 2015; Schnitzler et al., 2003). Pteropodids are a notable exception,

314 however, and rely either on vision or rudimentary forms of echolocation such as tongue or wing

315 clicks (Boonman et al., 2014; Jones and Teeling, 2006; Kulzer, 1956; Teeling, 2009). Most studies

316 of echolocation have focused on its role in prey capture or navigation through the environment

317 during forward flight. Little work to date has investigated echolocation behavior when

318 approaching stationary targets, such as roosts (but see (Tian and Schnitzler, 1997)) Interspecific

319 variation in echolocation behavior during landing could reveal patterns that coincide with

320 differences in impact forces and body rotations as bats call to sense the roost during approach.

321 Additionally, in the Pteropodidae, which do not possess laryngeal echolocation, landing behavior

322 could be constrained due to sensory limitations in their capacity to resolve details of potential

323 roosts with high temporal resolution during an approach flight.

$324 \quad$ Interspecific differences in wing morphology may also relate to variation in landing

325 mechanics. Because aerodynamic forces are highly dependent upon the velocity of airflow over the

326 wings, and landing occurs at low speeds, bats accomplish landing maneuvers using inertial forces

327 almost exclusively (Bergou et al., 2015). The wing's capacity to effect body rotation via inertial

328 torques is therefore related to their mass moment of inertia, which in turn is determined by the

329 distribution of mass within the wings. Studies that characterize interspecific differences in wing

330 mass distribution may therefore reveal a relationship between the wing's body mass-normalized

331 mass moment of inertia and the rotational complexity of landing maneuvers. For example,

332 variation in wing inertia could arise from interspecific differences in wing length or relative mass

333 of the bones, muscle and skin that comprise the wing, particularly in the distal regions.

Estimated ancestral landing mechanics provide support for a gliding bat ancestor

In bats, a group for which origins of powered flight in remain unresolved, studying the

338 evolution of flight itself. Despite a lack of fossil bat ancestors, most paleontological and

339 biomechanical investigations point to a gliding origin of bat flight. The hypothesized early bat

340 ancestor was likely arboreal, possessed gliding membranes made of skin, and is hypothesized to 
341 have performed gliding locomotion similar to that observed in extant mammalian gliders (Bishop,

342 2008; Curet et al., 2012; Gunnell and Simmons, 2012; Simmons et al., 2008).

343 If bat flight has its origins in gliding locomotion, then we would expect that ancestral bats

344 might have landed similarly to extant gliding mammals. Mammalian gliders execute landings that

345 rely almost exclusively on pitching rotations and result in high-impact forces (Bahlman et al., 2012;

346 Bishop, 2007, 2006; Byrnes et al., 2008; Paskins et al., 2007). The four-point landings observed in

347 extant bats are a plausible next step for landing maneuvers because they would require only

348 addition of further pitching to the basic glider landing pattern to facilitate landing on the

349 underside of roosts instead of on the vertical side of tree trunks. Indeed, stochastic character

350 mapping provides evidence that the common ancestor of bats performed a four-point landing

351 maneuver, which relies chiefly on pitching rotations with negligible contributions from yaw and

352 roll, and is characterized by high peak impact forces (Riskin et al., 2009). Our biomechanical study

353 of landing therefore provides additional support for the gliding origin of flight in bats.

Broader implications: bat conservation and adaptive radiation

Like most of the earth's biodiversity, bats are vulnerable to human disturbance, whether it

357 be through anthropogenic climate change or more proximate issues, such as deforestation, both of

358 which affect the availability and quality of roosts. If landing mechanics are associated with roosting

359 habits then they may affect the extent to which certain species are robust to displacement via roost

360 destruction. Bats with highly specialized roosting ecologies are generally at higher risk for

361 extinction and are less prevalent in disturbed forest fragments (Herrera et al., 2018; Sagot and

362 Chaverri, 2015). In addition to the difficulties associated with locating suitable alternatives, species

363 with specialized landing maneuvers, such as Thyroptera tricolor (Boerma et al., 2019), may also

364 encounter a biomechanical barrier to establishing new roosts. In certain cases, the mechanics of

365 bat landing maneuvers may thus mediate roost access by prohibiting certain species from

366 successfully landing on new surfaces if displaced. Conversely, species whose landing styles are more

367 flexible and permissive, or those which are able to perform multiple landing styles, such as A.

368 jamaicensis and M. schreibersii, may be able to roost more easily on a diverse array of surfaces and

369 thus might be more robust to habitat destruction and deforestation due to anthropogenic

370 intervention and climate change. Analyses that probe the relationship between number of roost 
371 types used, landing style, and habitat range are among the future efforts that could help evaluate

372 this hypothesis.

373 Additionally, studies that integrate biomechanics with ecology and evolutionary history

374 have the potential to reveal key morphological or behavioral innovations that changed the way

375 lineages interacted with their environments and helped to drive adaptive radiations (Burress et al.,

376 2020; Burress and Wainwright, 2019; Muñoz, 2019; Muñoz et al., 2018; Muñoz and Price, 2019;

377 Stroud and Losos, 2016). Here, we suggest that roosting ecology and landing mechanics are

378 functionally linked, and given the broad biological importance of roosting for bat diversity, the

379 potential for landing mechanics to be a mediating factor during the evolution of diverse roosting

380 habits makes this a promising system for studying how ecological opportunity (roosting ecology),

381 form (wing morphology), and function (landing mechanics) interacted over the course of

382 diversification in bats. The extent to which these factors acted as drivers of speciation in certain

383 lineages is unclear, but the present study serves as a foundation for future inquiry these

384 evolutionary relationships.

Such future work would benefit first and foremost from increased sampling, both in terms of phylogenetic breadth and in the number of individuals per species. Sampling bats from the twelve families absent from our sample and pursuing additional sampling in those we included, especially bats with larger body size (>200 g) or specialized roosting ecologies, would strengthen inferences about the evolutionary history of landing mechanics and better resolve correlations between landing style and roosting ecology. Sampling more individuals per species would also provide a better understanding of the levels of intraspecific variation in impact force, landing style, and landing kinematics. However, we acknowledge that the difficulties of field-based biomechanics research may pose challenges for observing landing behavior in a wider array of species. Approaches that eliminate the measurement of impact forces will allow for broader sampling with videography because some species are difficult or impossible to train to land on a small force platform. Furthermore, recording landing videos at known roost locations rather than with captured individuals in a field-based flight arena might also permit broader sample while simultaneously documenting variations in landing style on natural roosts. 
401 such as wing mass distribution, which determines the inertial torques bats use to execute landings

402 (Bergou et al., 2015), and other skeletal features relating to limb stresses and landing impact forces.

403 Taken together, these efforts would determine whether there are clade-based links among roosting

404 habits, landing style, wing morphology, and diversification rates. If shifts in roosting ecology were

405 associated with speciation in certain lineages (e.g., stenodermatines), and if roosting ecology,

406 landing style, and wing morphology were linked, then one should detect significant shifts in

407 diversification rates for clades that arise following coordinated shifts in roosting habits and landing

408 style.

410 Conclusions

411 Resolving the connections among form (morphology), function (mechanics), and

412 environmental context (ecology) are central to understanding the evolutionary history of

413 organisms. While form-function (functional morphology) and form-environment (ecomorphology)

414 relationships are often the focus of evolutionary studies, determining linkages between mechanics

415 and ecology are equally critical to understanding how morphological and ecological variation

416 interact with the organismal performance on which selection acts. We have presented the first

417 evolutionary analysis of any aspect of flight dynamics in bats that links specific traits associated

418 with flight performance to a particular aspect of bat ecology. Our survey of landing mechanics

419 across a broad sample of bats revealed that interspecific variation in landing styles varies along a

420 mechanical continuum of rotational complexity and landing impact force, and that the physical

421 properties of bat roosts are associated with particular landing styles. Independent of phylogenetic

422 relationships, rotationally complex, low-impact landings (two-point) were positively associated with

423 stiff, horizontal roosts, whereas rotationally simple, higher-impact landings (three-or four-point)

424 were negatively associated with stiff roosts, and in some cases were positively associated with

425 roosting in compliant foliage or spatially constrained roosts in vegetation. These results highlight

426 the evolutionary interactions between locomotor mechanics and ecology, establish functional links

427 between landing mechanics and roosting ecology in bats, and suggest that these interactions may

428 be a factor both for mediating roost use and for driving diversification in certain clades. By

429 connecting roosting ecology to the biomechanics of landing, we now have the potential to identify

430 traits that are specifically associated with a particular form of locomotor behavior of known 
431 ecological relevance. This accomplishment lays the foundation for a broader understand of the

432 evolution of flight and wing architecture in this extraordinarily successful lineage of mammals. To

433 this end, future work should examine additional ecological and morphological correlates and

434 incorporate evolutionary rate analyses to better resolve how landing mechanics and roosting

435 ecology, and other traits interacted throughout bat evolution.

437 Materials and Methods

438 Focal taxa, field sites, and animal capture

439 We recorded 665 landings from 96 bats, representing 35 species, and 9 families (table1).

440 We collected all measurements from wild-caught bats except for Rousettus aegyptiacus and taxa from

441 Riskin et al. (2009) (C. perspicillata, G. soricina, and C. brachyotis), which were captive-bred. Our

442 field sites were located in Lamanai, Orange Walk, Belize (Lamanai Outpost Lodge); Barú,

443 Puntarenas, Costa Rica (Haciénda Barú Biological Research Station); Tabachka, Bulgaria (Siemers

444 Bat Research Station, Max Planck Institute); and Shandong, China (Shandong University). We

445 captured bats using mist-netting, hand-netting, and harp traps.

Landing experiments

At each field site, we observed bat landings within a temporary flight corridor $(3 \times 1.5 \times 2$ m) (length $\mathrm{x}$ width $\mathrm{x}$ height). For all bats except T. tricolor (see Boerma et al. 2019), we covered the walls and ceiling with smooth plastic sheeting to prevent bats from landing anywhere but on a

451 ceiling-mounted landing platform, which was covered with stiff plastic mesh that provided a

452 favorable attachment surface for landing bats. We trained wild-caught bats to land on the platform

453 by positively reinforcing successful landings with food rewards (fruit and juice for frugivorous bats,

454 mealworms for insectivorous bats, and water for all bats), and recorded their landing maneuvers

455 with a synchronized array of three high speed video cameras (Phantom Miro M340, Vision

456 Research, Wayne, NJ, USA; 800 frames per second, 1000 us exposure; Lenses: Sigma DC 17 -

$45750 \mathrm{~mm}$ 1:28 EX HSM, SIGMA Corporation, Ronkonkoma, NY, USA) and three LED lights

458 (Veritas Constellation 120, Integrated Design Tools, Pasadena, CA, USA).

459 Sample sizes for number of species, number of individuals per species, and number of

460 landings per individual were subject to species availability at field sites and the extent to which 
461 wild-caught individuals were amenable to training. Previous studies documented extremely low,

462 and in some cases nonexistent, intraspecific variation in landing style (Boerma et al., 2019; Riskin

463 et al., 2009). We therefore accepted samples of one individual per species, but required at least two

464 landings per individual. We trained a subset of 65 individuals (18 species) to land on a ceiling-

465 mounted force plate (ATI nano17, ATI Industrial Automation, Apex, NC, USA fitted with

466 custom acrylic mounting and landing plates). We used a custom MATLAB script to sample impact

467 forces at $1000 \mathrm{~Hz}$, and to synchronize data collection between the force transducer and the high

468 speed cameras using a post-trigger initiated at the end of a landing event.

470 Ceiling reaction forces

471 We filtered the force profiles using a zero-phase $2^{\text {nd }}$ order low-pass Butterworth filter with a

472 cutoff frequency of $100 \mathrm{~Hz}$, which attenuates high-frequency oscillations and electrical noise while

473 preserving the primary peaks associated with landing impact. Although filtering diminishes the

474 absolute magnitude peak forces, accurate comparisons among individuals for all force components

475 are preserved as long as they have been filtered using the same parameters (Boerma et al., 2019;

476 Riskin et al., 2009). Our filtering parameters match those used by previous investigations of bat

477 landing impact forces (Riskin et al., 2009 and Boerma et al., 2019). We normalized landing impact

478 forces to each individual's bodyweight (BW), calculated from the difference between an unloaded

479 plate just prior to landing and the bat's hanging weight once landed (mass also verified prior to

480 data collection using a Pesola scale), then extracted peak 3D impact force into the plate for each

481 landing. We averaged peak impact forces for each individual prior to statistical tests.

483 Definitions of categorical variables: landing style and roosting ecology

484 We used high speed videography to categorize bat landings according to the convention

485 established in Riskin et al. 2009, which names landing styles according to the number of limbs

486 that make initial contact at landing impact with the roost. Landing styles include two-point

487 landings (both hind limbs), three-point landings (both hind limbs plus one thumb claw), and four-

488 point landings (both thumb claws plus both hind limbs) (figure1, landing style insets,

489 Supplemental Videos 1 - 5). 
We classified the roosting habits of each species according to published observations (table 1), using categories for roosting guilds outlined in Voss et al. 2016 and Garbino \& Tavares 2018,

492 with modifications. Our roosting categories included: cavity in standing tree (CST), exposed on

493 standing tree (EST), unmodified foliage (FOL-UF), furled leaf-tubed (FOL-TB), foliage modified

494 into leaf-tents (FOL-LT), termite or ant nests (TAN), rocks and/or caves (R/C), and rock crevices

495 (CREV).

497 Phylogenetic analyses: Ancestral state reconstruction, phylogenetic ANOVA, and phylogenetic logistic

498 regression

499 We used a published time-calibrated molecular phylogeny (Shi and Rabosky, 2015), pruned

500 to our focal taxa, for all phylogenetic analyses (excluding A. watsoni, which was not included in the

501 Shi \& Rabosky tree), using the Phytools R-package (Revell, 2018, 2011). We then assigned one

502 landing style as a discrete character to each taxon according to its most-often observed landing style

503 (table 1).

$504 \quad$ We conducted an ancestral state reconstruction using stochastic character mapping

505 (Huelsenbeck et al., 2003), as implemented in the make.simmap function of the R package

506 phytools, to reconstruct the evolutionary history of landing styles among sampled taxa. We used

507 the fitDiscrete function in the R package Geiger (Harmon et al., 2007) to compare the fit of four

508 different models for the transition matrix of the stochastic character mapping procedure: equal

509 rates, symmetric, all rates different, and meristic. The equal rates model yielded the lowest AICc

510 score, thus we selected this model, which gave all state changes equal probability, and computed

511 the posterior probability for each landing style at internal nodes from 1000 simulated stochastic

512 maps.

513 Next, we used phylogenetic generalized least squares regression (PGLS), implemented in

514 the R function pgls from the package Caper (Orme, 2018) to explore the extent to which landing

515 impact force is predicted by points of contact. Here, we estimated phylogenetic signal using the

516 maximum likelihood value of Pagel's lambda and treated points of contact and peak 3D landing

517 impact force as continuous variables. We log-transformed impact forces to ensure normality. We

518 then computed a phylogenetic ANOVA (10000 iterations) with post-hoc tests using the

519 phylANOVA function in the R package phytools to test for pairwise differences in log-peak 
520 landing impact forces among landing styles. Peak impact force was the response variable and

521 landing style was the factor. We omitted two species from these analyses due to an inability to

522 unambiguously designate them as a two-, three-, or four-point landing: M. schreibersii due to its high

523 degree of behavioral variability and T. tricolor because it performs a specialized landing maneuver to

524 alight on a vertical substrate (Boerma et al., 2019), rather than beneath a horizonal roost as in the

525 landing experiments for our other sampled taxa.

526 We used phylogenetic logistic regression with Firth's correction (Ives and Garland, 2009),

527 as implemented in the R package, phylolm (Ho and Ané, 2014), to test the hypothesis that landing

528 styles are associated with the physical properties of roosts. We applied 2000 bootstrap replicates to

529 generate confidence intervals for and test the significance of the model coefficients, $ß$, which relate

530 to the probability of observing a particular landing style (categorical response variable) given a

531 particular roosting ecology (categorical predictor variables). Positive coefficients indicate a positive

532 association between predictor and response variables, whereas negative coefficients denote a

533 negative relationship. We excluded T. tricolor from this analysis because it is the only sampled

534 taxon to perform its landing maneuver and to roost in tubular furled leaves. We compared two

535 models of roosting habits, the latter of which aggregated multiple roost types according to their

536 physical properties, thereby testing our hypothesis that diverse roost types that share physical

537 properties are correlate with landing style. The models were as follows: 1) a null model in which we

538 assigned each taxon's roosting ecology according to its most-commonly cited roost type (table 1),

539 and 2) an alternate model in which we aggregated roosting ecologies that include stiff, primarily

540 horizontal surfaces (CST, EST, and R/C) into a single category, spatially-constrained, horizontal

541 roosts in vegetation (FOL-LT and TAN) into a second category, compliant horizonal roosts (FOL-

542 UF), and crevices (CREV). We compared the explanatory power of each model using Akaike's

543 information criterion (AIC).

545 Acknowledgements

546 The authors are grateful for Nancy Simmons, Brock Fenton, Gloriana Chaverri, Rolf Mueller,

547 Holger Goerlitz, Stephan Greif, José Pablo Barrantes, Antonia Hubacheva, Theresa Hügel, and

548 those who attended the annual Belize Batathons for coordinating access to international field sites

549 and assisting in bat capture and experiments. We thank the Max Planck Institute for Ornithology, 
the Shandong University-Virginia Tech International Laboratory, the Lamanai Outpost Lodge, and the Hacienda Barú Biological Research Station for facilitating our field work. We thank

552 Kenny Breuer and Tom Roberts for providing force transducers, invaluable electronics guidance,

553 and assistance with experiments in the field. We also thank Cosima Schunk, Jorn Cheney, Jeremy

554 Rehm, Andrea Rummel, Lawrence Wang, and Erika Tavares for assistance with experiments and

555 animal husbandry.

557 Competing Interests

558 The authors declare no competing or financial interests.

Funding

561 Sigma Xi Grants in Aid of Research (GIAR) - DBB

562 SICB Fellowship for Graduate Student Travel (FGST) - DBB

563 Bushnell Research and Education Fund - DBB

- Figure 1-Source Data 1: This .csv file contains the raw peak impact force data, in units of bodyweight, for each recorded landing. Impact forces were recorded at $1000 \mathrm{~Hz}$, normalized to the individual's body mass, and smoothed using a zero-phase $2^{\text {nd }}$ order lowpass Butterworth filter with a cutoff frequency of $100 \mathrm{~Hz}$, parameters which are identical to those of previous bat landing studies. The total (resultant) force into the ceiling was calculated and the peak extracted for each landing.

- Figure 1-Source Data 2: This .csv file contains the mean peak impact forces for each individual. These values were used to generate Figure 1.

- Figure 1-Source Data 3:

- Figure 2-Source Data 1: This .tree file is the phylogeny from Shi and Rabosky (2015) used for all phylogenetic analyses in this study. The tree was trimmed to include only our focal species prior to any analyses.

- Figure 2-Source Data 2: This .csv file contains the source data for the stochastic character mapping and ancestra state reconstruction for landing style.

- Table 2-Source Data 1: This .csv file contains the source data for the phylogenetic logistic regression results summarized in Table 2.

- PGLS phylANOVA-Source Data 1: This .csv file contains the source data (Taxon, Landing Style, and mean peak impact force) for the phylogenetic generalized least squares regression and phylogenetic ANOVA with pairwise comparisons. This data file omits Thyroptera tricolor from both analyses because it is the only species to perform its specialized four-point landing and to roost in furled leaf tubes. It also omits Miniopterus schreibersii because its 
landing style was equivocal. See Supplemental File 3 for a version that includes Thyroptera tricolor.

- Supplemental File 1: Posterior probabilities for landing style at each node in the phylogeny shown in Figure 2. Posterior probabilities were estimated using an equal rates model for 1000 simulated stochastic character maps.

\section{References}

614

Altringham JD. 2011. Roosting and feeding ecologyBats: From Evolution to Conservation.

- Supplemental Video 1: Two-point landing - Rhinolophus ferrumequinum

- Supplemental Video 2: Three-point - Artibeus jamaicensis

- Supplemental Video 3: Four-point landing - Sturnira parvidens

- Supplemental Video 4: Specialized four-point landing - Thyroptera tricolor

- Supplemental Video 5: Four-point landing on cave wall - Myotis myotis

623 Aulagnier S, Mitchell-Jones AJ, Zima J, Haffner P, Moutou F, Chevalier J. 2018. Mammals of

Amador LI, Arévalo RLM, Almeida FC, Catalano SA, Giannini NP. 2018. Bat Systematics in the Light of Unconstrained Analyses of a Comprehensive Molecular Supermatrix. Journal of Mammalian Evolution 25:1-34. doi:10.1007/s10914-016-9363-8

Arbour JH, Curtis AA, Santana SE. 2019. Signatures of echolocation and dietary ecology in the adaptive evolution of skull shape in bats. Nature Communications 1-13. doi:10.1038/s41467019-09951-y

Europe, North Africa and the Middle East, Bloomsbury Wildlife. Bloomsbury Wildlife. 
625

626

627

628

629

630

631

632

633

634

635

636

637

638

639

640

641

642

643

644

645

646

647

648

649

650

651

652

653

654

655

656

657

Bahlman JW, Swartz SM, Riskin DK, Breuer KS. 2012. Glide performance and aerodynamics of non-equilibrium glides in northern flying squirrels (Glaucomys sabrinus). Journal of The Royal Society Interface 10:20120794-20120794. doi:10.1098/rsif.2012.0794

Barbour T. 1932. A peculiar roosting habit of bats. The Quarterly review of biology 7:307-312.

Bergou AJ, Swartz SM, Vejdani H, Riskin DK, Reimnitz L, Taubin G, Breuer KS. 2015. Falling with style: Bats perform complex aerial rotations by adjusting wing inertia. PLoS biology 13:e1002297. doi:10.1371/journal.pbio.1002297

Bishop KL. 2008. The evolution of flight in bats: narrowing the field of plausible hypotheses. The Quarterly review of biology 83:153-169.

Bishop KL. 2007. Aerodynamic force generation, performance and control of body orientation during gliding in sugar gliders (Petaurus breviceps). The Journal of experimental biology 210:2593-2606. doi:10.1242/jeb.002071

Bishop KL. 2006. The relationship between 3-D kinematics and gliding performance in the southern flying squirrel, Glaucomys volans. Journal of Experimental Biology 209:689-701. doi:10.1242/jeb.02062

Boerma DB, Barrantes JP, Chung C, Chaverri G, Swartz SM. 2019. Specialized landing maneuvers in Spix's disk-winged bats ( Thyroptera tricolor) reveal linkage between roosting ecology and landing biomechanics. The Journal of experimental biology 222:jeb204024-9. doi:10.1242/jeb.204024

Bogdanowicz W. 1994. Myotis daubentonii. Mammalian Species 1. doi:10.2307/3504215

Bonser RHC. 1999. Branching out in locomotion. Journal of Experimental Biology 1-5.

Boonman A, Bumrungsri S, Yovel Y. 2014. Nonecholocating Fruit Bats Produce Biosonar Clicks with Their Wings. Current Biology 24:2962-2967. doi:10.1016/j.cub.2014.10.077

Brigham RM. 1991. Flexibility in foraging and roosting behaviour by the big brown bat (Eptesicus fuscus). Canadian Journal of Zoology 69:117-121. doi:10.1139/z91-017

Brunet AK, Medellín RA. 2001. The species-area relationship in bat assemblages of tropical caves. Journal of Mammalogy 82:1114-1122. doi:10.1644/15451542(2001)082<1114:tsarib $>2.0$. co;2

Burress ED, Martinez CM, Wainwright PC. 2020. Decoupled jaws promote trophic diversity in cichlid fishes. Evolution 74:950-961. doi:10.1111/evo.13971

Burress ED, Wainwright PC. 2019. Adaptive radiation in labrid fishes: A central role for functional innovations during $65 \mathrm{My}$ of relentless diversification. Evolution 73:346-359. doi:10.1111/evo.13670 
Byrnes G, Lim NTL, Spence AJ. 2008. Take-off and landing kinetics of a free-ranging gliding mammal, the Malayan colugo (Galeopterus variegatus). Proceedings of the Royal Society B: Biological Sciences 275:1007-1013. doi:10.1098/rspb.2007.1684

Campbell P, Reid NM, Zubaid A, Adnan AM, Kunz TH. 2006. Comparative Roosting Ecology of Cynopterus (Chiroptera: Pteropodidae) Fruit Bats in Peninsular Malaysia. Biotropica 38:725-734. doi:10.1111/j.1744-7429.2006.00203.x

Catto CMC, Racey PA, Stephenson PJ. 1995. Activity patterns of the serotine bat (Eptesicus serotinus) at a roost in southern England. Journal of Zoology 235:635-644. doi:10.1111/j.1469-7998.1995.tb01774.x

Chapman F. 1932. A home-making bat. Natural History 555-556.

Chaverri G, Kunz TH. 2006. Roosting Ecology of the Tent-Roosting Bat Artibeus watsoni (Chiroptera: Phyllostomidae) in Southwestern Costa Rica. Biotropica 38:77-84.

Choe JC, Timm RM. 1985. Roosting site selection by Artibeus watsoni (Chiroptera: Phyllostomidae) on Anthurium ravenii (Araceae) in Costa Rica. Journal of Tropical Ecology 1:241-247. doi:10.1017/s0266467400000316

Cloutier D, Thomas DW. 1992. Carollia perspicillata. Mammalian Species 417:1-9.

Curet OM, Swartz SM, Breuer KS. 2012. An aeroelastic instability provides a possible basis for the transition from gliding to flapping flight. Journal of The Royal Society Interface 10:20120940-20120940. doi:10.1098/rsif.2012.0940

Dakin R, Segre PS, Straw AD, Altshuler DL. 2018. Morphology, muscle capacity, skill, and maneuvering ability in hummingbirds. Science 359:653-657. doi:10.1126/science.aao7104

Demes B, Jungers WL, Gross TS. 1995. Kinetics of leaping primates: influence of substrate orientation and compliance. American Journal of Physical Anthropology 419-429.

Dumont ER, Davalos LM, Goldberg A, Santana SE, Rex K, Voigt CC. 2012. Morphological innovation, diversification and invasion of a new adaptive zone. Proceedings of the Royal Society B: Biological Sciences 279:1797-1805. doi:10.1098/rspb.2011.2005

Dumont ER, Samadevam K, Grosse I, Warsi OM, Baird B, Dávalos LM. 2014. Selection for mechanical advantage underlies multiple cranial optima in new world leaf-nosed bats. Evolution 68:1436-1449. doi:10.1111/evo.12358

Eliason CM, Straker L, Jung S, Hackett SJ. 2020. Morphological innovation and biomechanical diversity in plunge-diving birds. Evolution 74:1514-1524. doi:10.1111/evo.14024 
Fenton MB, Bernard E, Bouchard S, Hollis L, Johnston DS, Lausen CL, Ratcliffe JM, Riskin DK, Taylor JR, Zigouris J. 2001. The bat fauna of Lamanai, Belize: Roosts and trophic roles. Journal of Tropical Ecology 17:511-524.

Fenton MB, Vonhof MJ, Bouchard S, Gill SA, Johnston DS, Reid FA, Riskin DK, Standing KL, Taylor JR, Wagner R. 2000. Roosts used by Sturnira lilium (Chiroptera : Phyllostomidae) in Belize. Biotropica 32:729-733.

Funakoshi K, Zubaid A. 1997. Behavioural and reproductive ecology of the dog-faced fruit bats, Cynopterus brachyotis and C. horsfieldi, in a Malaysian rainforest. Mammal Study 22:95-108. doi:10.3106/mammalstudy.22.95

Garbino GST, Tavares V da C. 2018. Roosting ecology of Stenodermatinae bats (Phyllostomidae): evolution of foliage roosting and correlated phenotypes. Mammal Review 30:239-15. doi:10.1111/mam.12114

Geva-Sagiv M, Las L, Yovel Y, Ulanovsky N. 2015. Spatial cognition in bats and rats: from sensory acquisition to multiscale maps and navigation. Nature reviews Neuroscience 16:94108. doi:10.1038/nrn3888

Gunnell GF, Simmons NB. 2012. Evolutionary History of Bats, Cambridge University Press. Cambridge University Press.

Harmon LJ, Weir JT, Brock CD, Glor RE, Challenger W. 2007. GEIGER: investigating evolutionary radiations. Bioinformatics 24:129-131. doi:10.1093/bioinformatics/btm538

Hernández-Meza B, Domínguez-Castellanos Y, Ortega J. 2005. Myotis keaysi. Mammalian Species 785:1-3. doi:10.1644/785.1

Herrera JP, Duncan N, Clare E, Fenton MB, Simmons N. 2018. Disassembly of Fragmented Bat Communities in Orange Walk District, Belize. Acta Chiropterologica 20:147-13. doi:10.3161/15081109acc2018.20.1.011

Herzig-Straschil B, Robinson GA. 1978. On the ecology of the fruit bat, Rousettus aegyptiacus leachi (A. Smith, 1829) in the Tsitsikama Coastal National Park. Koedoe 21. doi:10.4102/koedoe.v21i1.965

Higham TE, Rogers SM, Langerhans RB, Jamniczky HA, Lauder GV, Stewart WJ, Martin CH, Reznick DN. 2016. Speciation through the lens of biomechanics: locomotion, prey capture and reproductive isolation. Proceedings of the Royal Society B: Biological Sciences 283:20161294-39. doi:10.1098/rspb.2016.1294

Ho L si T, Ané C. 2014. A Linear-Time Algorithm for Gaussian and Non-Gaussian Trait Evolution Models. Systematic Biology 63:397-408. doi:10.1093/sysbio/syu005 
722

723

724

725

726

727

728

729

730

731

732

733

734

735

736

737

738

739

740

741

742

743

744

745

746

747

748

749

750

751

752

753

Horáček I, Benda P. 2004. Hypsugo savii (Bonaparte, 1837) - Alpenfledermaus In: Krapp F, editor. Hanbuch Der Säugetiere Europas. AULA-Verlag. pp. 912-941.

Huelsenbeck JP, Nielsen R, Bollback JP. 2003. Stochastic Mapping of Morphological Characters. Systematic Biology 52:131-158. doi:10.1080/10635150390192780

Ives AR, Garland T. 2009. Phylogenetic Logistic Regression for Binary Dependent Variables. Systematic Biology 59:9-26. doi:10.1093/sysbio/syp074

Jones G, Teeling E. 2006. The evolution of echolocation in bats. Trends in Ecology \& Evolution 21:149-156. doi:10.1016/j.tree.2006.01.001

Jr. JKJ, Smith JD, Genoways HH. 1973. Annotated Checklist of Mammals of the Yucatan Peninsula, Mexico. I. Chiroptera. Occasional Papers, Museum of Texas Tech University 132.

Kulzer E. 1956. Flughunde erzeugen orientierungslaute durch Zungenschlag. Naturwissenschaften 43:117-118.

Kunz TH, Fenton MB. 2006. Bat Ecology, University of Chicago Press. University of Chicago Press.

Kunz TH, Lumsden LF. 2003. Ecology of Cavity and Foliage Roosting Bats In: Kunz TH, Fenton MB, editors. Bat Ecology. pp. 3-89.

Kwiecinski GG, Griffiths TA. 1999. Rousettus egyptiacus. Mammalian Species 1. doi:10.2307/3504411

Lausen CL, Barclay RMR. 2003. Thermoregulation and roost selection by reproductive female big brown bats (Eptesicus fuscus) roosting in rock crevices. Journal of Zoology 260:235-244. doi:10.1017/s0952836903003686

Lausen CL, Barclay RMR. 2002. Roosting behaviour and roost selection of female big brown bats (Eptesicus fuscus) roosting in rock crevices in southeastern Alberta. Canadian Journal of Zoology 80:1069-1076. doi:10.1139/z02-086

Moore TY, Cooper KL, Biewener AA, Vasudevan R. 2017. Unpredictability of escape trajectory explains predator evasion ability and microhabitat preference of desert rodents. Nature Communications 8:1-9. doi:10.1038/s41467-017-00373-2

Muñoz MM. 2019. The Evolutionary Dynamics of Mechanically Complex Systems. Integrative and Comparative Biology 59:705-715. doi:10.1093/icb/icz077

Muñoz MM, Hu Y, Anderson PSL, Patek SN. 2018. Strong biomechanical relationships bias the tempo and mode of morphological evolution. eLife 7:19699. doi:10.7554/elife.37621 
754

755

756

757

758

759

760

761

762

763

764

765

766

767

768

769

770

771

772

773

774

775

776

777

778

779

780

781

782

783

784

785

Muñoz MM, Price SA. 2019. The Future is Bright for Evolutionary Morphology and Biomechanics in the Era of Big Data. Integrative and Comparative Biology 59:599-603. doi:10.1093/icb/icz121

Niu H, Wang N, Zhao L, Liu J. 2007. Distribution and underground habitats of cave-dwelling bats in China. Animal Conservation 10:470-477. doi:10.1111/j.1469-1795.2007.00136.x

Nowak RM. 1999. Chiroptera: BatsWalkers Mammals of the World. The Johns Hopkins University Press.

Orme D. 2018. The caper package: comparative analysis of phylogenetics and evolution in R.

Papadatou E, Butlin RK, Altringham JD. 2008. Seasonal Roosting Habits and Population Structure of the Long-fingered Bat Myotis capaccinii in Greece. Journal of Mammalogy 89:503-512. doi:10.1644/07-mamm-a-163r1.1

Paskins KE, Bowyer A, Megill WM, Scheibe JS. 2007. Take-off and landing forces and the evolution of controlled gliding in northern flying squirrels Glaucomys sabrinus. The Journal of experimental biology 210:1413-1423. doi:10.1242/jeb.02747

Reid F. 2009. A Field Guide to the Mammals of Central America and Southeast Mexico, Oxford University Press. Oxford University Press.

Revell LJ. 2018. Package 'phytools' 1-195.

Revell LJ. 2011. phytools: an R package for phylogenetic comparative biology (and other things). Methods in Ecology and Evolution 3:217-223. doi:10.1111/j.2041210x.2011.00169.x

Riskin DK, Bahlman JW, Hubel TY, Ratcliffe JM, Kunz TH, Swartz SM. 2009. Bats go headunder-heels: the biomechanics of landing on a ceiling. Journal of Experimental Biology 212:945-953. doi:10.1242/jeb.026161

Rojas D, Warsi OM, Dávalos LM. 2016. Bats (Chiroptera: Noctilionoidea) Challenge a Recent Origin of Extant Neotropical Diversity. Systematic Biology 65:432-448. doi:10.1093/sysbio/syw011

Sagot M, Chaverri G. 2015. Effects of roost specialization on extinction risk in bats. Conservation Biology 29:1666-1673. doi:10.1111/cobi.12546

Santana SE, Grosse IR, Dumont ER. 2012. Dietary hardness, loading behavior, and the evolution of skull form in bats. Evolution 66:2587-2598. doi:10.1111/j.1558-5646.2012.01615.x

Schluter D. 2009. Evidence for ecological speciation and its alternative. Science 323:737-741. doi:10.1126/science. 1160006 
Schnitzler H-U, Moss CF, Denzinger A. 2003. From spatial orientation to food acquisition in echolocating bats. Trends in Ecology \& Evolution 18:386-394. doi:10.1016/s01695347(03)00185-x

Shi JJ, Rabosky DL. 2015. Speciation dynamics during the global radiation of extant bats. Evolution 69:1528-1545. doi:10.1111/evo.12681

Simmons NB, Seymour KL, Habersetzer J, Gunnell GF. 2008. Primitive Early Eocene bat from Wyoming and the evolution of flight and echolocation. Nature 451:818-821. doi:10.1038/nature06549

Simmons NB, Voss RS. 1998. The mammals of Paracou, French Guiana: A neotropical lowland rainforest fauna part - 1. Bats. Bulletin of the American Museum of Natural History 1-219.

Stroud JT, Losos JB. 2016. Ecological Opportunity and Adaptive Radiation. Annual Review of Ecology, Evolution, and Systematics 47:507-532. doi:10.1146/annurev-ecolsys-121415032254

Tan KH, Zubaid A, Kunz TH. 1997. Tent construction and social organization in Cynopterus brachyotis (Muller) (Chiroptera: Pteropodidae) in Peninsular Malaysia. Journal of Natural History 31:1605-1621. doi:10.1080/00222939700770861

Teeling EC. 2009. Hear, hear: the convergent evolution of echolocation in bats? Trends in Ecology \& Evolution 24:351-354. doi:10.1016/j.tree.2009.02.012

Thomas DW, Fenton MB. 1978. Notes on the dry season roosting and foraging behaviour of Epomophorus gambianus and Rousettus aegyptiacus (Chiroptera :Pteropodidae). Journal of Zoology 186:403-406. doi:10.1111/j.1469-7998.1978.tb03929.x

Tian B, Schnitzler H-U. 1997. Echolocation signals of the Greater Horseshoe bat (Rhinolophus ferrumequinum) in transfer flight and during landing. The Journal of the Acoustical Society of America 101:2347-2364. doi:10.1121/1.418272

Timm RM. 1987. Tent Construction by Bats of the Genera Artibeus and Uroderma In: D PB, Timm RM, editors. Studies in Neotropical Mammalogy Essays in Honor of Philip Hershkovitz. pp. 187-212.

Timm RM. 1985. Artibeus phaeotis. Mammalian Species 1-6.

Voss RS, Fleck DW, Strauss RE, Velazco PM, Simmons NB. 2016. Roosting Ecology of Amazonian Bats: Evidence for Guild Structure in Hyperdiverse Mammalian Communities. American Museum Novitates 3870:1-43. doi:10.1206/3870.1

Wainwright PCP, Alfaro MEM, Bolnick DID, Hulsey CDC. 2005. Many-to-One Mapping of Form to Function: A General Principle in Organismal Design? Integrative and Comparative Biology 45:256-262. doi:10.1093/icb/45.2.256 
820 Wilkinson GS. 1984. Reciprocal food sharing in the vampire bat. Nature 308:181-184.

821 Wilson DE, Findley JS. 1977. Thyroptera tricolor. Mammalian Species 71:1-3.

822 Zhang L, Jones G, Zhang J, Zhu G, Parsons S, Rossiter SJ, Zhang S. 2009. Recent Surveys of 823 Bats (Mammalia: Chiroptera) from China. I. Rhinolophidae and Hipposideridae. Acta

824 Chiropterologica 11:71-88. doi:10.3161/150811009x465703

825 